\title{
THE RELATIONSHIP OF THE GONOCOCCAL COMPLEMENT FIXATION TEST TO THE DIAGNOSIS AND TREATMENT OF GONORRHEA
}

By T. E. OSMOND, M.B.

Mr. President, Ladies and Gentlemen,-Lest I should appear in a false position here to-night let me hasten to explain that I do not regard myself as co-reader of a paper but rather as a supporter of my old colleague, Dr. Price, whom I should like to congratulate on a most interesting paper which has left very little for me to say. When I promised to speak on the subject my intention was merely to act as a foil to the author of the paper and, so to speak, to dot his "i's" and cross his " $t$ 's" ; perhaps also to offer some criticism-constructive as well as destructive, I hope, though I should add that I am in complete agreement with him on most points and therefore need not reiterate them. Moreover, I think I can claim to view the subject from the point of view both of the pathologist and of the clinician, since I have been in close touch with both aspects of gonorrhœa almost continuously for over twenty-five years. Ever since I9I8, when I commenced to work on the gonococcal complement fixation test, I have tried to interest people in this test which Oliver and I $\mathbf{1}, \mathbf{2}$ found very specific since we got very few false positive results. To my mind it offers a very close parallel with the Wassermann reaction. It becomes positive within about ten days of the appearance of the first clinical signs, rises to its maximum in a few weeks, and then tends to fade away ; the more the tissues react the stronger the result of the test. A positive reaction is diagnostic in a very large percentage of cases though a negative does not exclude the disease. A positive reaction in any case is far more reliable than a negative. In my experience false positives do not occur in more than 0.3 to 0.6 per cent. of casesand, contrary to what some people believe, syphilis will 
not give a positive gonococcal complement fixation reaction ; for cure a series of negatives, not a single one, is required. Moreover, false positives are rare with either test if it is properly carried out. In this connection let me sound a note of warning. I believe that there are relatively as many unreliable gonococcal complement fixation test techniques as there are unreliable Wassermann reactions. Carpenter ${ }^{3}$ has no opinion of the gonococcal complement fixation test as carried out in America, and quotes a series of 28 cases in which there were no symptoms nor history of gonococcal infection in which 20 gave positive reactions (7I per cent.) ; also 4 other cases whose blood was sent to eight different laboratories which returned the most discordant results, each serum being returned as positive from one laboratory and negative from another. Jacoby ${ }^{4}$ and others in an evaluation of the test think it has a limited usefulness, since they report I3 to I5 per cent. of non-specific positive reactions. You cannot treat this test as a side issue, carrying out a dozen or so a week with antigen which someone has given you and expect to get reliable results ; you have got to keep in touch with the patients, check your results and know that the clinician is standing at your elbow like a big bogey ready to leap upon you when you go wrong. Some clinicians take for gospel any pathological report but not so the V.D. specialist.

In my opinion the gonococcal complement fixation test should be carried out just as often as the Wassermann reaction - that is when the patient is first seen, every few months whilst the disease evolves and several times after clinical cure in order to establish bacteriological cure.

Now a positive reaction in a patient who has got clinical gonorrhœa is both to be expected and to be hoped for ; it demonstrates the fact that the patient is reacting and may be regarded in general as a favourable sign according to Dixon and Priestley. ${ }^{5}$ But what of the negative reaction when gonococci can be demonstrated? You have all met the patient who goes on and on just dribbling, no matter what you do; he will frequently give a negative reaction and this may be due to one of two factors-soil or seed. Some patients' tissues seem to fail to react to the organism-in fact take things lying down-and the tissues and germ appear to establish a sort of equilibrium - a live and let live attitude ; on the 


\section{RELATIONSHIP OF THE GONOCOCCAL TEST}

other hand, certain strains of gonococci seem to be much less virulent than others, and so cause much less reaction on the part of the patient's tissues-here again the test may be negative. This is not surprising in view of the work of Casper ${ }^{6}$ who found that most strains of gonococci could be classified as Type I or Type II, but that certain ones, notably those obtained from long-standing chronic cases of gonorrhœa conformed to neither type, failed to produce the appropriate polysaccharides and moreover proved poorly antigenic in vitro (just as they do in vivo). So do not grouse at the pathologist if he returns a negative reaction when gonococci are present, any more than you would if he returned a negative Wassermann reaction in a case of, say, gumma, aneurysm or tabes.

Now I should like to refer to a few of the points which Dr. Price has made. The "closed" and "open" focus theory is after all only a theory. If you test the sera of cases of Littritis, which are good examples of closed foci, you will frequently find the blood test negative, whilst the roaring gonorrhœa, pouring pus, which has been lucky enough apparently to escape posterior infection, may give a positive reaction, and are posterior urethritis, prostatitis and vesiculitis necessarily closed foci ? Generally I do not like his use of the expression " weakly positive," especially when he refers to a \pm reaction which many people call doubtful-that is a reaction which shows a partial but incomplete hæmolysis in the key tube. To my mind a reaction can only be one of three things-positive, negative or doubtful; in my experience the occurrence of \pm reactions is far too common in non-gonorrhœal cases for one to dub them weakly positive any more than one would $\mathrm{a} \pm$ Wassermann reaction. They may be significant but they are not diagnostic which is what the word positive should mean. I must confess that these doubtful reactions occur only too frequently amongst our tests at St. Thomas's Hospital. The explanation lies I think in the make-up of the antigen which is far too anti-complementary or, shall I say, that the anti-complementary antigenic ratio is far too high-much higher than it is in the case of the Wassermann reaction. The fact of using neat serum, too, may predispose to doubtful reactions-since many normal sera contain anti-complementary substances. It might prove useful to attempt to remove these substances 


\section{BRITISH JOURNAL OF VENEREAL DISEASES}

somewhat on the lines recommended by Auguste ${ }^{7}$ who treats his sera with dilute $\mathrm{HCl}$ and buffers them with phosphates. I am sorry to say I have not had an opportunity of trying this in the case of gonorrhœa, but it seems to be successful with the Wassermann reaction. Certainly much more research work is necessary before we shall have a gonococcal antigen anything like as efficient as the Wassermann one.

It is interesting to speculate on one type of case which Dr. Price quotes, namely that of acute gonorrhœa involving only the anterior urethra which at most shows a \pm blood reaction and is rapidly cured. I do not suppose anyone here deludes himself into thinking that he cures his cases of gonorrhœa with, say, permanganate irrigations; surely it is the tissues which in the end kill off the invading organisms, and if they do so very rapidly, why do we not find definite evidence of antibody production as shown by a strongly pósitive serum test ? Perhaps the explanation lies in the fact that the strain of gonococci in question is a very avirulent one-or have the tissues elaborated some form of antibody which is not a complement-fixing one, and might this not explain some of the apparently false negative results? On the other hand it is a common observation that a case which suddenly develops an epididymitis will often show a remarkable diminution or even cessation of discharge ; these cases invariably show a very strong serum reaction, and is it not this sudden flood of antibody which is the explanation of the discharge stopping?

Vulvo-vaginitis of children often perplexes the clinician both as regards diagnosis and test of cure. We get relatively few cases at St. Thomas's Hospital-or rather the ones we get are mostly sent on elsewhere so that the number of positive serum reactions which we meet is small-not nearly so high a proportion as that recorded by Dr. Price. Perhaps the explanation lies in the fact that, as Reichert, Epstein, Jung and Colwell ${ }^{8}$ claim, in the large majority of these cases the cervix uteri becomes involved. Certainly this is not my experience, but my experience is small, and I shall be glad to hear the opinions of others. Zoon ${ }^{9}$ does not regard the test as of much value in this condition. Cross-fixation is a very debatable subject-and is difficult to prove or disprove. I can only say that I believe it does occur-though rarely. I have 


\section{RELATIONSHIP OF THE GONOCOCCAL TEST}

in mind two cases who repeatedly gave positive reactions in varying strengths and who, as far as one could judge, were not suffering from gonorrhœa, but who seemed more than usually susceptible to the common cold. Some years ago Dr. Oliver ${ }^{10}$ did some very useful experimental work on this subject, and came to the conclusion that infections with $\mathbf{M}$. catarrhalis could cause sera to react with gonococcal antigens.

However, cross-fixation will not explain away more than a very small percentage of the unexpectedly positive reactions which we meet, and it behoves us all to go over the case very thoroughly when such a reaction does crop up.

Vaccines offer another problem. I doubt if the matter is quite so clear cut as Dr. Price would have you believe. Those vaccines which represent a simple suspension of organisms-particularly if they are made from old or " chronic" strains - may have little effect on the blood reaction if given in the usual doses, but such vaccines as the detoxicated of Thomson or ecto-antigen of Dimond in my experience have a marked effect and the blood reaction does not tend to disappear quickly.

Coming to the use of Prontosil and allied substances, it is conceivable that where the serum reaction remains negative till the patient is cured, the drug has killed off all the germs before the complement fixation test had time to become positive-possibly the urethritis has remained anterior. This is a very desirable result, but distinctly uncommon, in my experience. I have an idea that these drugs are more efficient when the patient has developed a certain amount of immunity, so that I prefer to find the patients' blood reaction positive, or to try to make it become positive, when prescribing those drugs.

As regards interpretation of results, I am largely in agreement with Dr. Price-but there is one subject on which I hope members will give their views to-night and that is the "fixed positive." This reaction is very much on a par with "Wassermann-fastness," that is to say, in certain cases it seems to remain positive more or less indefinitely in spite of all one can do, yet often the most careful and detailed search reveals no evidence of the presence of gonococci. Such a reaction often occurs in old prostatitis and epididymitis cases, and one is led to wonder if they are any more contagious than old Wasser- 
mann-fast latent cases of syphilis. Perhaps the explanation of Moore and Padget $\mathbf{1 1}$ as regards syphilis-viz., that sero-resistance may result entirely from the persistence of well-established immunity-is the correct one. Dörffel ${ }^{\mathbf{1 2}}$ thinks that, at any rate in a proportion of cases, a persistent positive reaction does not mean that gonococci are still present, and cites I9 cases clinically cured, of which 7 became negative in 4 to II months, 3 in I 2 to I6 months, and 9 persisted for 2 years. He also followed up I 26 cases of which 9 were positive after I year, 7 after 2 to 5 years, and I each for $7,8, I_{4}, I_{7}$, and 35 years. He also injected a number of cases-who had not had gonorrhœa-with vaccine, and they remained positive for from II weeks to 6 months. Even supposing the gonococcus is still present, is it not possible that it has become so avirulent as to be harmless? I only offer this as a suggestion.

In any case most of us have come across cases which continue to give a positive serum reaction yet go on for years without showing any clinical signs, and I have known several who have married and produced healthy children without apparently infecting their wives-I think I should have heard of it if they had! Strongly positive reactions may with advantage be titrated out and the results expressed as the highest dilution of serum which gives a positive reaction; e.g., I in 5 , I in IO, $I$ in 20. This is useful also in observing the rise in positivity as the disease progresses, and contrariwise as showing the fall in strength of the reaction as the disease dies out ; in late cases, too, a steady fall in the strength of the reaction may be an indication of the adequacy of the treatment.

In general medicine too the gonococcal complement fixation test may be of the greatest value in rheumatic and arthritic conditions and in epididymitis of doubtful. origin-since the test will nearly always be positive in such cases if they are due to the gonococcus.

As regards test of cure, I would emphasise what Dr. Price has said, namely that it is a number of negatives, not one that is necessary. More especially is a negative reaction valuable if it has previously been positive, whilst the fact of a positive reaction steadily weakening until finally it becomes negative and remains so, is the best evidence of cure of all. In any case time is a factor in 


\section{RELATIONSHIP OF THE GONOCOCCAL TEST}

establishing the fact of cure in gonorrhœa as well as negative tests just as it is in syphilis, and I do not suppose anyone here would allow a man who had had gonorrhœa to marry until a certain minimum time had elapsed after clinical cure.

Finally I would say that the doctor who attempts to treat gonorrhœa without the use of the gonococcal complement fixation test definitely handicaps himself and is on a par with him who treats syphilis without the aid of the Wassermann or other serum reaction. The treatment of these diseases cannot be stereotyped, and the more we try to understand the immunological factors involved and apply the knowledge so gained the more likely are we to attain success.

\section{REFERENCES}

(I) Osmond, T. E. : Lancet, I922, $i$, II43

(2) Osmond, T. E., and Oliver, J. O. : B.J.V.D., October, I929.

(3) Carpenter, C. M. : Jour. Amer. Med. Assoc., I937, 109, No. I8, pp. 428-30.

(4) Jacoby, A., Wishengrad, M., and Koopman, J. : Amer. Jour. Syph., 1938, 22, 32-38.

(5) Dixon, H. B. F., and Priestley, A. H. : Lancet, I9I9, ii, 964.

(6) CASPER, W. A. : Jour. Bact., I937, 34, 353-9.

(7) Auguste, C.: Ann. Inst. Pasteur., I936, 56, I7-45 (34 refs.).

(8) Reichert, J. L., Epstein, I. M., Jung, Ruth and Colwell, Charlotte: Amer. Jour. Dis. Child., I937, 54, 459-94 (26 refs.).

(9) Zoon: Acta Dermato-Venereologica, I928, 9, 318.

(Io) Oliver, J. O. : Jour. of Hyg., I929, 39, No. 3.

(II) Moore, J. E., and PAdget, P.: Jour. Amer. Med. Assoc., I938, 110, 96-100.

(I2) Dörffel, J. : Arch.f. Dermat. u. Syph., 1933, 169.

I have had a letter from Colonel Harrison who is very sorry he had no time in the rush to leave for Jamaica to write a commentary; he wishes me to say: (I) he admires Dr. Price's work very greatly and wishes to add his congratulations to those which he is sure to receive on this paper, and (2) the only point on which he would join issue with him (or practically the only point of any importance) is in the significance of a persistent gonococcal complement fixation reaction. Having watched numbers of such cases for numbers of years, taking very many specimens from them with negative results he does not believe that the persistent reaction necessarily means 


\section{BRITISH JOURNAL OF VENEREAL DISEA SES}

that the patient is a gonococcus carrier; he would of course test such a case three times as severely as he would a serologically negative one, but having then failed to find gonococci he would certainly not withhold permission to marry. 